\title{
Composição química e concentração mínima bactericida de dezesseis óleos essenciais sobre Escherichia coli enterotoxigênica
}

SOUZA, A.A."; DIAS, N.A.A.2; PICCOLI, R.H.2; BERTOLUCCI, S.K.V. ${ }^{*}$

Universidade Federal de Lavras, Programa de Pós-graduação em Plantas Medicinais, Aromáticas e Condimentares, Departamento de Agricultura, Caixa Postal 3037, Campus Universitário, Lavras - MG, CEP 37200-000; '2Universidade Federal de Lavras, Departamento de Ciência dos Alimentos, Caixa Postal 3037, Campus Universitário, Lavras - MG, CEP 37200-000. *Autor para correspondência: suzan@dag.ufla.br

RESUMO: Este trabalho teve por objetivo avaliar o efeito bactericida in vitro de dezesseis óleos essenciais sobre Escherichia coli enterotoxigênica (ETEC). Dentre os óleos essenciais estudados, três foram extraídos in situ por arraste a vapor e treze foram adquiridos comercialmente. Todos os óleos foram analisados por CG-EM e CG-DIC. A atividade bactericida foi avaliada pelo método de microdiluição utilizando-se caldo triptona de soja e microplacas de poliestireno de 96 poços, com posterior plaqueamento das culturas em ágar triptona de soja. Os óleos essenciais de Cinnamomum cassia e de Thymus vulgaris apresentaram concentração mínima bactericida (CMB) de 0,12\% e 0,25\%, respectivamente. Já os óleos comerciais de Syzygium aromaticum e Origanum vulgare apresentaram ambos CMB de 0,50\% e os óleos extraídos in situ de Cymbopogon citratus e Origanum vulgare apresentaram ambos CMB de 1,00\%. Os dezesseis óleos essenciais apresentaram composição química qualitativa e quantitativa distintas. As análises químicas dos óleos essenciais de Cinnamomum cassia e de Thymus vulgaris tiveram a presença majoritária de $E$-cinamaldeído (84,52\%) e timol (50,89\%). Conclui-se que os óleos de C. cassia e $T$. vulgaris foram os mais eficazes na inibição do crescimento in vitro dessa bactéria, a qual possui diferentes níveis de sensibilidade dependendo da composição química do óleo.

Palavras-chave: Patógeno alimentar, ETEC, antimicrobianos naturais, atividade bactericida, cromatografia gasosa.

\begin{abstract}
Determination of minimum bactericidal concentration of sixteen essential oils on enterotoxigenic Escherichia coli. This study aimed to evaluate the bactericidal effect in vitro of sixteen essential oils on enterotoxigenic Escherichia coli (ETEC). Among the essential oils, three were extracted in situ by steam distillation and thirteen were purchased commercially. All oils were analyzed by GC-MS and GC-FID. The bactericidal activity was evaluated by the microdilution method using tryptone soy broth, and 96-well polystyrene microplates with subsequent plating of the cultures in tryptone soy agar. Cinnamomum cassia and Thymus vulgaris essential oils showed minimal bactericidal concentration (MBC) $0.12 \%$ and $0.25 \%$, respectively. Both commercial oils of Syzygium aromaticum and Origanum vulgare showed MBC of $0.50 \%$ and the oils extracted in situ Origanum vulgare and Cymbopogon citratus showed both $\mathrm{MBC}$ of $1.00 \%$. The sixteen essential oils pointed out distinct qualitative and quantitative chemical composition. Chemical analysis of Cinnamomum cassia and Thymus vulgaris oils had the predominant presence of $E$-cinnamaldehyde $(84.52 \% \pm 0.07 \%)$ and thymol $(50.89 \%$ $\pm 0.31 \%)$. In conclusion, $T$. vulgaris and $C$. cassia oils were the most effective in inhibiting in vitro growth of this bacterium, which has different sensitivity levels depending on the chemical composition of the oil.
\end{abstract}

Keywords: Food pathogen, ETEC, natural antimicrobial, bactericidal activity, gas chromatography. 


\section{INTRODUÇÃO}

A presença de microrganismos nos alimentos pode, além de reduzir a vida de prateleira, causar toxinfecções nos consumidores (Melo et al., 2005). Bactérias do grupo dos coliformes fecais são utilizadas como indicadores de condições higiênicosanitárias de água e alimentos. A Escherichia coli é uma bactéria Gram-negativa que faz parte dos coliformes termotolerantes e ocorre em fezes de animais de sangue quente, assim como o homem (Silva et al., 2014). A presença de microrganismos indicadores como Escherichia coli em produtos processados indica, provavelmente, contaminação posterior ao processamento e pode sugerir uso de práticas inadequadas de manipulação e higiene (Lima et al., 2007).

Apesar de E. coli serem largamente consideradas como comensais, alguns isolados têm o potencial de provocar infecções. E. coli patogênicas podem ser divididas em três subgrupos principais dependendo de sua patogenicidade: comensais ou não patogênicas, $E$. coli patogênicas intestinais e E. coli patogênicas extraintestinais. As E. coli patogênicas intestinais incluem diferentes patotipos, dos quais se inclui a $E$. coli enterotoxigênica (Moriel et al., 2010). AETEC causa a gastroenterite conhecida como diarreia dos viajantes, que tem como quadro clínico diarreia líquida, dor abdominal, febre baixa, náusea e mal-estar. A ETEC, normalmente não é responsável por toxinfecções alimentares em países com bom padrão sanitário e boas práticas de preparação dos alimentos. Porém, em países com precárias condições higiênico-sanitárias a contaminação da água com esgoto pode levar à contaminação destes (CVE, 2002).

$O$ interesse em antimicrobianos naturais tem se expandido nos últimos anos em resposta a demanda dos consumidores por aditivos naturais. Durante as duas últimas décadas, conservantes naturais têm sido investigados para aplicações práticas (Tiwari et al., 2009). Dentre diversos outros produtos naturais, extratos vegetais e óleos essenciais vêm sendo largamente estudados para uso como conservantes naturais de alimentos e, têm demonstrado promissoras propriedades antioxidantes, antimicrobianas e antiparasitárias (Okpekon et al., 2004; Sokmen et al., 2004; Sacchetti et al., 2005; Ferreira et al., 2006; Boulanouar et al., 2013).

Em particular, os óleos essenciais podem afetar tanto o invólucro externo quanto o citoplasma das células bacterianas, sendo a membrana celular o primeiro alvo. Isto ocorre devido à hidrofobicidade destes e de seus componentes, que permitem que eles se difundam através da bicamada fosfolipídica (Nazzaro et al., 2013). O mecanismo de ação dos óleos essenciais sobre as bactérias está relacionado à perturbação da membrana citoplasmática, danos nas proteínas da membrana, coagulação do citoplasma, alteração no fluxo de elétrons, interrupção da força próton motriz, alteração do transporte ativo e redução do pool de ATP intracelular (Burt, 2004; Nazzaro et al., 2013).

O presente trabalho teve por objetivo avaliar o efeito bactericida in vitro de dezesseis óleos essenciais sobre Escherichia coli enterotoxigênica (ETEC), bem como relacionar a composição química desses óleos com esta atividade.

\section{MATERIAL E MÉTODOS Obtenção dos óleos essenciais}

A atividade bactericida de dezesseis óleos essenciais sobre ETEC foi avaliada. Destes, treze foram adquiridos da empresa Ferquima Indústria e Comércio Ltda. e os demais extraídos in situ no Laboratório de Fitoquímica do Departamento de Agricultura (DAG) da Universidade Federal de Lavras (UFLA). Os óleos essenciais comerciais empregados no estudo estão listados na Tabela 1.

Os óleos essenciais de Cymbopogon citratus (DC) Stapf. (capim-limão), Ocimum basilicum L. (manjericão) e Origanum vulgare L. (orégano) foram obtidos das folhas frescas. As três espécies vegetais foram cultivadas em solo com adubação orgânica (esterco bovino) em canteiros localizados no Horto de Plantas Medicinais do DAG/ UFLA, Lavras (2114' $43544^{\circ} 59^{\prime} 59 \mathrm{~W}$, média anual de precipitação de $1530 \mathrm{~mm}$, temperatura média de $20,4^{\circ} \mathrm{C}$ e $919 \mathrm{~m}$ altitude), Minas Gerais, Brasil. As exsicatas de $C$. citratus, $O$. basilicum e $O$. vulgare estão depositadas no herbário ESAL sob os registros 18409, 18406 e 22156, respectivamente. Folhas das três espécies foram coletadas entre os meses de fevereiro a abril de 2014 às 9:00 h da manhã. As folhas de $C$. citratus foram cortadas em fragmentos de $1,0 \pm 0,2 \mathrm{~cm}^{2}$ e as de $O$. basilicum e $O$. vulgare foram utilizadas inteiras. Os óleos essenciais das três espécies foram extraídos por destilação por arraste a vapor, em destilador Marconi® MA480, por 120 minutos. O óleo essencial foi purificado por decantação, e armazenado em refrigerador a $4^{\circ} \mathrm{C}$, até a realização dos ensaios biológicos e análises químicas por CG-EM e CG-DIC.

\section{Análises químicas dos óleos essenciais}

As análises químicas dos óleos essenciais foram realizadas por Cromatografia de Fase Gasosa empregando-se um Cromatógrafo Agilent ${ }^{\circledR}$ 7890A, operado com sistema de processamento de dados HP GC ChemStation Ver. A.01.14, equipado com injetor/amostrador automático CombiPAL Autosampler System (CTC Analytic AG, 
TABELA 1. Óleos essenciais comerciais utilizados no estudo.

\begin{tabular}{lcc}
\hline Nome científico & Nome comum & Parte usada * \\
\hline Cinnamomum cassia Nees ex Blume & Canela & Folhas, casca \\
Citrus aurantifolia Swingle & Limão tahiti & Pericarpo \\
Citrus nobilis Lour. & Mandarina & Pericarpo \\
Foeniculum vulgare Mill. & Funcho doce & Sementes \\
Illicium verum Hook. & Anis estrelado & Frutos e sementes \\
Mentha piperita L. & Menta & Folhas \\
Myristica fragans Houtt. & Noz moscada & Frutos \\
Ocimum basilicum L. & Manjericão & Folhas \\
Origanum vulgare L. & Orégano & Folhas \\
Piper nigrum L. & Pimenta preta & Frutos \\
Rosmarinus officinalis L. & Alecrim & Folhas \\
Syzygium aromaticum Thumb. & Cravo da Índia & Botões florais \\
Thymus vulgaris L. & Tomilho branco & Folhas \\
\hline
\end{tabular}

*Com exceção dos frutos cítricos que foram extraídos por prensagem a frio, os demais, segundo a empresa Ferquima ${ }^{\circledR}$, foram extraídos por destilação por arraste a vapor.

Switzerland) e um Detector de lonização em Chama (DIC). As amostras foram preparadas diluindo-se o óleo essencial em acetato de etila $(1 \%, v / v)$. O volume de injeção foi de $1,0 \mu \mathrm{L}$, no modo split a uma razão de injeção de 50:1. Empregou-se coluna capilar de sílica fundida HP-5MS $(30 \mathrm{~m}$ de comprimento $\times 250 \mu \mathrm{m}$ de diâmetro interno $\times$ $0,25 \mu \mathrm{m}$ de espessura do filme) (Califórnia, EUA). Hélio foi utilizado como gás de arraste com fluxo de $1,0 \mathrm{~mL} / \mathrm{min}$; as temperaturas do injetor e do detector foram mantidas em $240^{\circ} \mathrm{C}$. Empregou-se uma rampa de temperatura de $3^{\circ} \mathrm{C} /$ min de $60^{\circ} \mathrm{C}$ a $200^{\circ} \mathrm{C}$, seguido de uma rampa de $10^{\circ} \mathrm{C} / \mathrm{min}$ até $270^{\circ} \mathrm{C}$, mantendo-se em condição isotérmica por 1 minuto. As concentrações dos constituintes foram expressas pela média da porcentagem de área relativa dos picos cromatográficos \pm o desvio padrão de 3 amostras analisadas. Devido à complexidade química e o grande número de amostras (dezesseis óleos essenciais), os resultados analíticos foram apresentados apenas para os cinco constituintes de maior área relativa.

As análises qualitativas foram realizadas em Cromatógrafo Agilent $₫ 7890$ A acoplado a um detector seletivo de massas Agilent $\circledast$ MSD 5975C (Agilent Technologies, Califórnia, EUA), operado por ionização de impacto eletrônico a 70 eV, em modo varredura, a uma velocidade de 1,0 scan/s, com intervalo de aquisição de massas de 40-400 m/z. As condições operacionais foram as mesmas empregadas nas análises por CG-DIC. Os constituintes químicos foram identificados por comparação dos seus índices de retenção relativos à coinjeção de uma solução padrão de $n$-alcanos (C8-C20, Sigma-Aldrich ${ }^{\circledR}$, St. Louis, USA) e por comparação dos espectros de massas do banco de dados da biblioteca NIST/EPA/NHI (Nist,
2008) e de literatura (Adams, 2007). Os índices de retenção foram calculados usando a equação de Van den Dool \& Kratz (1963) e para as atribuições foram consultados índices de retenção de literaturas (Adams, 2007).

\section{Microrganismo, manutenção, padronização e obtenção do inóculo}

Os ensaios microbiológicos foram realizados no Laboratório de Microbiologia de Alimentos do Departamento de Ciência dos Alimentos da UFLA. O microrganismo utilizado foi Escherichia coli enterotoxigênica (ETEC) cedida pelo Laboratório de Enterobactérias (LABENT) do Instituto Oswaldo Cruz (IOC/FIOCRUZ). A cultura estoque, armazenada em meio de congelamento (glicerol - $15 \mathrm{~mL}$; peptona bacteriológica - 0,5 g; extrato de levedura $-0,3 \mathrm{~g}$; $\mathrm{NaCl}-0,5 \mathrm{~g}$; água destilada $-100 \mathrm{~mL} ; \mathrm{pH}$ entre 7,2 e 7,4), foi ativada pela transferência de alíquotas da cultura para caldo triptona de soja (Tryptone Soya Broth - TSB, Himedia $\left(\right.$ ) e incubada a $37^{\circ} \mathrm{C}$ por 24 horas. Após ativação, transferiu-se $40 \mu \mathrm{L}$ da cultura para $200 \mathrm{~mL}$ de TSB, e incubou-se a $37^{\circ} \mathrm{C}$, sendo o crescimento acompanhado por leituras periódicas de absorbância, a 600nm e quantificação de células viáveis em ágar triptona de soja (Tryptone Soya Agar - TSA, Himedia ${ }^{\circledR}$ ) com incubação a $37^{\circ} \mathrm{C}$ por 24 horas. A cultura foi padronizada em $10^{8} \mathrm{UFC} \cdot \mathrm{mL}^{-1}$ na absorbância de 0,5 a 1,0 nm.

\section{Determinação da Concentração Mínima Bactericida}

A determinação da concentração mínima bactericida $(\mathrm{CMB})$ foi realizada empregando-se o método de microdiluição em caldo utilizando-se microplacas de poliestireno com 96 poços (CLSI, 
2003). Soluções com diferentes concentrações dos óleos essenciais foram preparadas em TSB adicionado de $0,5 \%$ de Tween 80 nas concentrações: $2,00 \% ; 1,00 \% ; 0,50 \% ; 0,25 \% ; 0,12 \% ; 0,06 \%$;e $0,03 \%$. Após as alíquotas de $150 \mu \mathrm{L}$ das diferentes soluções serem transferidas para as cavidades das microplacas, $10 \mu \mathrm{L}$ de cultura padronizada foram inoculadas em cada cavidade. As microplacas foram vedadas e incubadas a $37^{\circ} \mathrm{C}$ por 24 horas com posterior plaqueamento por microgota em TSA e incubação a $37^{\circ} \mathrm{C}$ por 24 horas.

O experimento foi conduzido em triplicata com três repetições para cada réplica, utilizando-se controle positivo (TSB acrescido de $0,5 \%$ de Tween 80 e cultura) para cada repetição.

A pureza da cultura foi avaliada periodicamente por coloração de Gram e plaqueamento em ágar eosina azul de metileno (EMB) com incubação a $37^{\circ} \mathrm{C}$ por 24 horas.

\section{RESULTADOS E DISCUSSÃO}

Os resultados indicaram que os dezesseis óleos essenciais selecionados apresentaram diferentes magnitudes de atividade biocida sobre ETEC (Tabela 2). O óleo essencial com maior atividade biocida sobre ETEC foi o de C. cassia, com $\mathrm{CMB}$ de $0,12 \%$, seguido pelo óleo essencial de $T$. vulgaris com CMB de $0,25 \%$.

Com uma atividade bactericida moderada, os óleos essenciais de $S$. aromaticum e $O$. vulgare comerciais apresentaram CMB de $0,50 \%$ e os

TABELA 2. Concentração mínima bactericida (CMB) de óleos essenciais sobre a bactéria Escherichia coli enterotoxigênica in vitro.

\begin{tabular}{lc}
\hline Óleos essenciais & CMB $(\%)(\mathrm{v} / \mathrm{v})$ \\
\hline Cinnamomum cassia & 0,12 \\
Citrus aurantifolia & $>2,00$ \\
Citrus nobilis & $>2,00$ \\
Cymbopogon citratus & 1,00 \\
Foeniculum vulgare & $>2,00$ \\
Illicium verum & $>2,00$ \\
Mentha piperita & 2,00 \\
Myristica fragans & $>2,00$ \\
Ocimum basilicum & $>2,00$ \\
Ocimum basilicum (UFLA) & $>2,00$ \\
Origanum vulgare & 0,50 \\
Origanum vulgare (UFLA) & 1,00 \\
Piper nigrum & $>2,00$ \\
Rosmarinus officinalis & $>2,00$ \\
Syzygium aromaticum & 0,50 \\
Thymus vulgaris & 0,25 \\
\hline
\end{tabular}

de O. vulgare e $C$. citratus extraídos na UFLA, apresentaram CMB de 1,0\%. Dentre os dezesseis óleos estudados, dez apresentaram CMB igual ou superior a $2 \%(\mathrm{v} / \mathrm{v})$ sobre ETEC, sendo eles M. piperita, C. aurantifolia, C. nobilis, F. vulgare, I. verum, $M$. fragans, O. basilicum (comercial e UFLA), $P$. nigrum e $R$. officinalis (Tabela 2).

A atividade antimicrobiana exercida pelos óleos essenciais tem sido descrita para uma ampla variedade de microrganismos, tanto Gram-positivos quanto Gram-negativos, os quais respondem de forma distinta e dependente da composição química dos óleos (Boulanouar et al., 2013; Burt, 2004; Solórzano-Santos \& Miranda-Novales, 2011). Deste modo, as diferenças observadas na atividade bactericida desses óleos sobre ETEC podem estar relacionadas as expressivas variações na composição química dos óleos (Tabela 3 ). As diferenças químicas foram observadas, principalmente, na classe dos monoterpenos hidrocarbonetos, cujos teores variaram de 1,3\% a $95,52 \%$; na classe dos monoterpenos oxigenados, desde não detectados até $84,07 \%$ e na classe de compostos fenólicos, desde não detectados até $94,75 \%$. Com isso, não foi possível relacionar a suscetibilidade de ETEC frente aos dezesseis óleos com base na classe química constitucional do óleo, já que houve óleos ricos em compostos fenólicos, como I. verum $(93,64 \%)$ e O. basilicum comercial $(86,74 \%)$, que apresentaram CMB maior que $2 \%$ e o óleo de C. cassia, rico no aldeído fenólico E-cinamaldeído, que apresentou CMB de 0,12\%.

O óleo de C. cassia foi constituído na sua totalidade de $94,75 \%$ de compostos fenólicos característicos da classe dos fenilpropanóides. A análise por CG-EM identificou três fenilpropanóides principais, dos quais $84,52 \%$ de E-cinamaldeído, $8,79 \%$ de $(E)$-o-metoxicinamaldeído e $1,44 \%$ de acetato de $E$-cinamila.

Já o óleo de T. vulgaris, que apresentou o segundo melhor resultado contra ETEC, foi composto de $30,88 \%$ de compostos da classe dos monoterpenos hidrocarbonetos, $4,46 \%$ de monoterpenos oxigenados e $53,82 \%$ de compostos fenólicos. No entanto, dentro do porcentual dos compostos fenólicos, $50,89 \%$ correspondeu ao teor de timol, um composto fenólico de origem biossintética da rota dos terpenos. Salienta-se ainda que, a classe dos monoterpenos hidrocarbonetos no óleo de T. vulgaris, foi constituída por $24,87 \%$ de $p$-cimeno e $5,91 \%$ de $\gamma$-terpineno.

Destacam-se ainda a composição química do óleo essencial de $O$. vulgare comercial e $S$. aromaticum que apresentaram CMB sobre ETEC de $0,50 \%$. No primeiro, a classe de monoterpenos hidrocarbonetos foi constituída na sua totalidade de $3,92 \%$ de $p$-cimeno e $3,93 \%$ de $\gamma$-terpineno;

Rev. Bras. PI. Med., Campinas, v.18, n.1, p.105-112, 2016. 
TABELA 3. Composição química principal dos óleos essenciais avaliados nos ensaios de efeito bactericida in vitro contra ETEC.

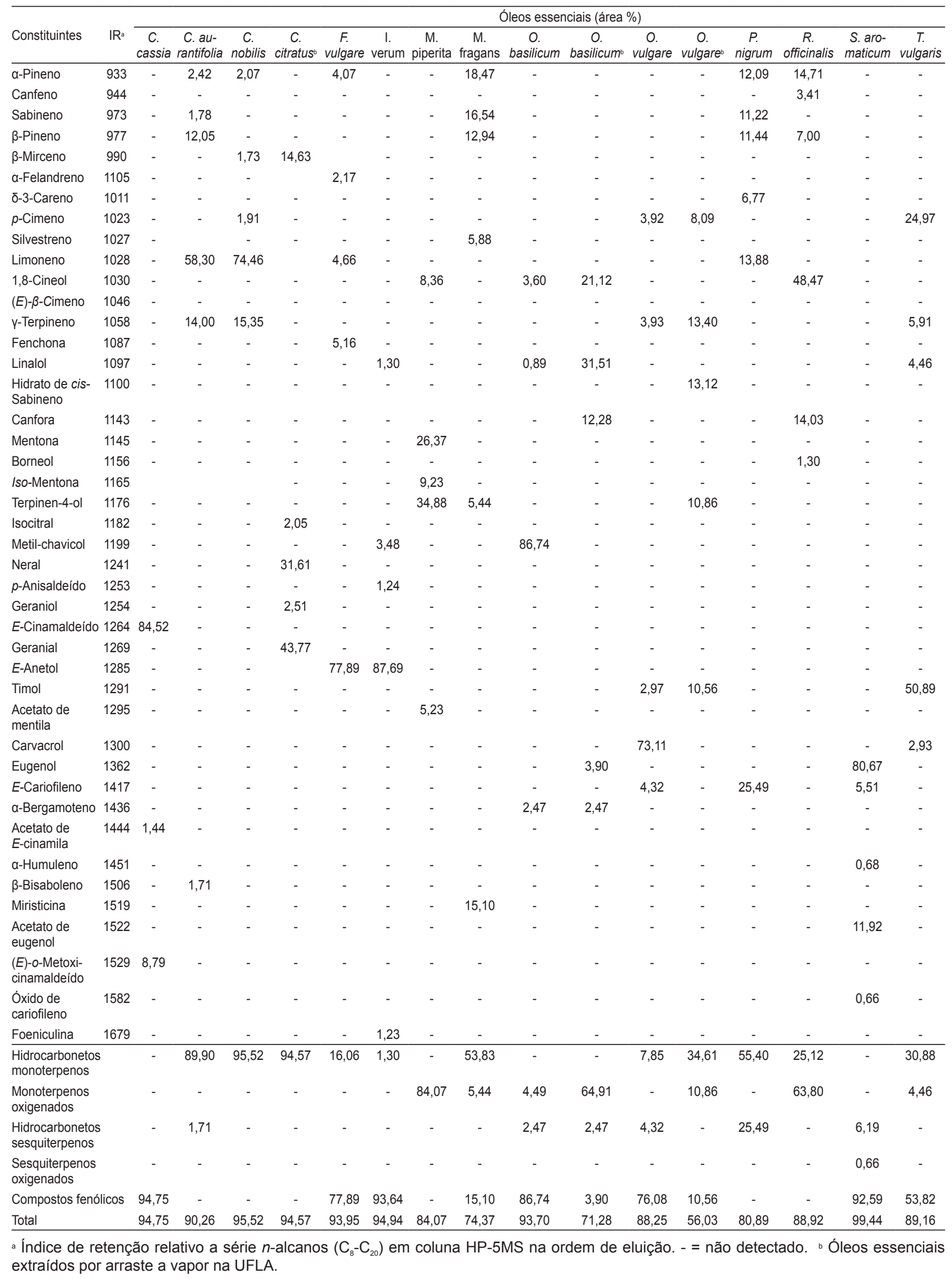

Rev. Bras. Pl. Med., Campinas, v.18, n.1, p.105-112, 2016. 
$4,32 \%$ de E-cariofileno (sesquiterpeno oxigenado); e, $76,08 \%$ de compostos fenólicos. Por sua vez, o óleo de $S$. aromaticum foi constituído de $6,19 \%$ de hidrocarbonetos sesquiterpênicos; $0,66 \%$ do sesquiterpeno oxigenado óxido de cariofileno; e, $92,59 \%$ de compostos fenólicos, sendo que destes, $80,67 \%$ correspondeu ao teor do fenilpropeno eugenol.

Os resultados do presente estudo corroboram com os resultados de Holley \& Patel (2005), que observaram que os óleos essenciais e seus constituintes fenólicos, como cinamaldeído, timol, carvacrol e eugenol foram eficazes contra muitos agentes patogênicos de origem alimentar, incluindo a E. coli O157:H7. Na literatura foram encontrados dois manuscritos que avaliaram a atividade antimicrobiana sobre ETEC. O primeiro foi publicado por Peñalver et al. (2005) que observaram maior capacidade inibitória do crescimento sobre bactérias da família Enterobacteriaceae em óleos ricos em compostos fenólicos, como carvacrol e timol. Nesse trabalho, os óleos essenciais de Origanum vulgare e diferentes espécies do gênero Thymus ( $T$. mastichina e $T$. zygis) apresentaram concentração mínima inibitória de $4 \%(\mathrm{v} / \mathrm{v})$. O segundo, foi realizado por Duarte et al. (2007) que avaliaram 29 óleos essenciais contra diferentes sorotipos de E. coli. Para os óleos de M. piperita, O. basiculum, O. vulgare e Thymus vulgaris, Duarte e colaboradores observaram concentração mínima inibitória acima de $1000 \mu \mathrm{g} / \mathrm{mL}$, não apresentando os dados de composição química, já que não foram os óleos mais eficazes.

Conforme Gutierrez et al. (2008), a ação antimicrobiana apresentada pelos óleos essenciais não depende unicamente da composição química, mas também das propriedades lipofílicas, da solubilidade em água, da potência dos grupos funcionais e da mistura de compostos com diferentes propriedades bioquímicas. No que se refere a potência do grupo funcional, o cinamaldeído é um aldeído aromático, já bem conhecido como agente antimicrobiano natural de patógenos contaminantes de alimentos. Seu mecanismo de ação tem sido associado à formação de base de Schiff com proteínas de membrana pela reação com seu grupo carbonílico livre, o que provoca danos na membrana celular (González-Aguilar et al., 2011, Wei et al., 2011).

Há evidências também que alguns constituintes presentes em pequenas quantidades nos óleos essenciais, como $y$-terpineno e $p$-cimeno, interferem na atividade antimicrobiana dos óleos facilitando a permeabilidade do carvacrol e timol na célula bacteriana (Silva et al., 2010; Romero et al., 2009), o que nesse caso poderia explicar a atividade bactericida dos óleos de $T$. vulgaris e $O$. vulgare comercial sobre ETEC. Já o modo de ação de compostos fenólicos em bactérias patogênicas ainda não está bem estabelecido. Acredita-se que fenóis hidrofóbicos, como timol e carvacrol também possam agir por alterações na permeabilidade da membrana celular. No entanto, investigações mais aprofundadas são necessárias para esclarecer os mecanismos de ação desses compostos (GonzálezAguilar et al., 2011).

As atividades antimicrobianas dos óleos de C. cassia e T. vulgaris, avaliadas por diferentes metodologias, já são bem relatadas na literatura para uma série de microorganismos patogênicos (Ooi et al., 2006; Oussalah et al., 2007; Abdollahzadeh et. al., 2014; Dussault et al., 2014; Pekmezovic et al., 2015). Assim, como estudos com outras cepas patogênicas de $E$. coli, como o estudo de Oliveira et al. (2012), que observaram atividade inibitória de $E$. coli enteropatogênica (EPEC) ao avaliarem os óleos essenciais de Melaleuca alternifolia (melaleuca), Cymbopogon flexuosus (capim-limão da Índia Oriental) e Cinnamomum cassia (canela cássia) pelo mesmo método utilizado neste trabalho. A CBM determinada para estes óleos foram de 0,06\% para óleo de C. cassia e $0,25 \%$ para os óleos de M. alternifolia e C. flexuosus. Santos et al. (2012) pesquisando a ação antibacteriana do óleo essencial de folhas de Piper malacophyllum (pariparoba) sobre E. coli ATCC 25922 pelo método de microdiluição em caldo, encontraram uma CMB de $3700 \mu \mathrm{g} / \mathrm{mL}$.

Embora a atividade antibacteriana dos óleos essenciais utilizados neste trabalho seja bem conhecida, estes ainda não haviam sido avaliados contra a cepa ETEC. Os resultados mostraram diferentes níveis de sensibilidade desta cepa de Escherichia coli frente aos dezesseis óleos essenciais. Estudos futuros podem ser realizados objetivando investigar os mecanismos de ação envolvidos na atividade anti-ETEC, visto que diferentes classes de compostos químicos estavam envolvidas na eficácia da atividade biocida desta bactéria e diversos são os fatores que podem interferir no crescimento e desenvolvimento bacteriano.

\section{CONCLUSÃO}

Escherichia coli enterotoxigênica apresenta diferentes níveis de sensibilidade frente à faixa de concentração de $0,03 \%$ a $2,00 \%$ dos dezesseis óleos essenciais estudados. A atividade anti-ETEC é dependente da composição química do óleo essencial. Os óleos de C. cassia e T. vulgaris, ricos em E-cinamaldeído e timol, respectivamente, foram os mais eficazes na inibição do crescimento in vitro de ETEC, o que indica potencialidades na conservação microbiológica de alimentos. 


\section{AGRADECIMENTOS}

À Fundação de Amparo à Pesquisa do Estado de Minas Gerais (FAPEMIG), Coordenação de Aperfeiçoamento de Pessoal de Nível Superior (CAPES) e ao Conselho Nacional de Desenvolvimento Científico e Tecnológico (CNPq) pelo apoio financeiro e concessão de bolsas.

\section{REFERÊNCIAS}

ADAMS, R.P. Identification of essential oil components by gas chromatography/ mass spectrometry. 4.ed. Illinois: Allured Publishing Corporation, 2007. 803p.

ABDOLLAHZADEH, E.; et al., Antibacterial activity of plant essential oils and extracts: The role of thyme essential oil, nisin, and their combination to control Listeria monocytogenes inoculated in minced fish meat. Food Control, v.35, p.177-83, 2014.

BOULANOUAR, B.; et. al. Antioxidant activities of eight Algerian plant extracts and two essential oils. Industrial Crops and Products, v.46, p.85-96, 2013.

BURT, S. Essential oils: their antibacterial properties and potential applications in foods: a review. International Journal of Food Microbiology, v. 94, n. 3, p.223 -253, 2004.

CLSI. Clinical Laboratory Standards Institute. Metodologia dos testes de sensibilidade a agentes antimicrobianos por diluição para bactérias de crescimento aeróbico: norma aprovada. 6.ed. São Paulo, v.23, M7-A6, 2003.

CVE. Centro de Vigilância Epidemiológica, Divisão de Doenças de Transmissão Hídrica e Alimentar. Manual das Doenças Transmitidas por Alimentos: Escherichia coli enterotoxigênica (ETEC), São Paulo: Secretaria de Estado da Saúde de São Paulo, 2002. Disponível em: http://ftp.cve.saude.sp.gov.br/doc_tec/ hidrica/ecoli_entero toxi.pdf. Acesso em: 16 set. 2014.

DUARTE, M.C.T. Activity of essential oils from Brazilian medicinal plants on Escherichia coli. Journal of Ethnopharmacology, v.111, p.197-201, 2007.

DUSSAULT, D.; et al., In vitro evaluation of antimicrobial activities of various comercial essential oils, oleoresin and pure compounds against food pathogens and application in ham. Meat Science, v. 96, p.514-20, 2014.

FERREIRA, A.; et al. The in vitro screening for acetylcholinesterase inhibition and antioxidant activity of medicinal plants from Portugal. Journal of Ethnopharmacology, v. 108, n.1, p.31-37, 2006.

GONZÁLEZ-AGUILAR, G.A.; et al. Natural antimicrobial compounds to preserve quality and assure safety of fresh horticultural prodice. In: RAI, M.; CHIKINDAS, $M$. (eds). Natural antimicrobials in food safety and quality. Cambridge: Cabi International, 2011. p. 277-282.

GUTIERREZ, J.; et al., The antimicrobial efficacy of plant essential oil combinations and interactions withfood ingredients. International Journal of Food Microbiology, v.124, p.91-97, 2008.

HOLLEY, R.A.; PATEL, D. Improvement in shelf-life and safety of perishable foods by plant essential oils and smoke antimicrobials. Food Microbiology, v.22, p.273-292, 2005.

LIMA, C.P.S.; et al. Presença de microrganismos indicadores de qualidade em farinha e goma de mandioca (Manihot esculenta Crantz). Revista APS, v.10, n.1, p.14-19, 2007.

MELO, N.R.; et al., Nisina: um conservante natural para alimentos. Revista Ceres, v.52, n.303, p.921938, 2005.

NAZZARO, F.; et al. Effect of essential oils on pathogenic bacteria. Pharmaceuticals, v.6, n.12, p.1451-1474, 2013.

NIST. NATIONAL INSTITUTE OF STANDARDS AND TECHNOLOGY. PC version 2.0 of the NIST/EPA/ NIH Mass Spectral Library, software. Gaithersburg: NIST, 2008.

OLIVEIRA, M.M.M.; et al. Control of planktonic and sessile bacterial cells by essential oils. Food and Bioproducts Processing, v.9, p. 809-818, 2012.

OKPEKON, T.; et al. Antiparasitic activities of medicinal plants used in Ivory Coast. Journal of Ethnopharmacology, v.90, n.1, p.91-97, 2004.

OOI, L.S.M.; et al. Antimicrobial activities of cinnamon oil and cinnamaldehyde from the chinese medicinal herb Cinnamomum cassia Blume. The American Journal of Chinese Medicine, v.34, n.3, p.511-22, 2006.

OUSSALAH, M.; et al. Inhibitory eVects of selected plant essential oils on the growth of four pathogenic bacteria: E. coli 0157:H7, Salmonella Typhimurium, Staphylococcus aureus and Listeria monocytogenes. Food Control, v.18, p.414-20, 2007.

PEKMEZOVIC, M.; et al. Development of kinetic model for testing antifungal effect of Thymus vulgaris $\mathrm{L}$. and Cinnamomum cassia L. essential oils on Aspergillus flavus spores and application for optimization of synergistic effect. Biochemical Engineering Journal, v.99, p.131-37, 2015.

PEÑALVER, P. et al. Antimicrobial activity of five essential oils against origin strains of the Enterobacteriaceae Family. Acta Pathologica, Microbiologica et Immunologica Scandinavica, v.113, p.1-6, 2005.

MORIEL, D.G.; et al. Identification of protective and broadly conserved vaccine antigens from the genome of extraintestinal pathogenic Escherichia coli. Proceedings of the National Academy of Sciences, v.107, n. 20, p. 9072-77, 2010.

ROMERO, A.L.; et al. Atividade do óleo essencial de tomilho (Thymus vulgaris L.) contra fungos fitopatogênicos. UNOPAR Científica Ciências Biológicas e da Saúde, v.11, n.4, p.15-18, 2009.

SACCHETTI, G.; et al. Comparative evaluation of 11 essential oils of different origin as functional antioxidants, antiradicals and antimicrobials in foods. Food Chemistry, v.91, n.4, p.621-632, 2005.

SANTOS, T.G.; et al. Composição química e avaliação da atividade antimicrobiana do óleo essencial das folhas de Piper malacophyllum (C. Presl.) C. DC. Química Nova, v.35, n.3, p.477-81, 2012.

SILVA, J.P.L.; et al. Óleo essencial de orégano: interferência da composição química na atividade frente a Salmonella Enteritidis. Ciência e Tecnologia de Alimentos, v.30, n.1, p.136-141, 2010.

SILVA, M.L.Q.; et al. Avaliação higiênico-sanitária dos 
restaurantes self-services e restaurantes populares da cidade de Juazeiro do Norte (CE) quanto a prevalência de Escherichia coli e Staphylococcus sp. Revista Interfaces: Saúde, Humanas e Tecnologia, v.2, n. especial, 2014.

SOKMEN, S.; et al. The in vitro antimicrobial and antioxidant activities of the essential oils and methanol extracts of endemic Thymus spathulifolius. Food Control, v. 15, n. 8, p. 627-634, 2004.

SOLÓRZANO-SANTOS, F.; MIRANDA-NOVALES, M.G. Essential oils from aromatic herbs as antimicrobial agents. Current Opinion in Biotechnology, v.23, p.1-6, 2011.

TIWARI, B.K.; et al. Application of Natural Antimicrobials for Food Preservation. Journal of Agricultural and Food Chemistry. v. 57, p.5987-6000, 2009.

VAN DEN DOOL, H.; KRATZ, P.D. A generalization of the retention index system including linear temperature programmed gas liquid partition chromatography. Journal of Chromatography, v.11, p.463-71, 1963.

WEI, Y.; et al. Mechanism of Vibrio cholerae autoinducer-1 biosynthesis. ACS Chem Biol, v.6, p.356-65, 2011. 